\title{
Intelligence quotient profile in myotonic dystrophy, intergenerational deficit, and correlation with CTG amplification
}

\author{
Peter Turnpenny, Caroline Clark, Kevin Kelly
}

\begin{abstract}
An abbreviated Weschler Adult Intelligence Scale Revised (WAIS-R) was used to assess verbal and arithmetical cognitive performance in 55 subjects with myotonic dystrophy (DM), covering all grades of disease severity, and 31 controls at $50 \%$ risk of inheriting DM. Scaled scores from the assessment were converted into an intelligence quotient (IQ) estimation on each person. Significant IQ differences were found between: (1) all 55 DM subjects (mean 90.2, SD 16.1) and 31 controls (102.6, SD 9.4), with no sex differences in either group; (2) 15 affected parents $(99 \cdot 3$, SD $12 \cdot 2)$ and their affected children (88.1, SD 17.2), where significance was dependent on parental sex being female; and (3) 15 pairs of affected sibs (89.6, SD 13.2) and their normal sibs $(100 \cdot 2$, SD 7.6). IQ steadily declined as (1) the age of onset of signs and symptoms decreased, and (2) the CTG expansion size increased. The correlation appeared to be more linear with age of onset. The correlation of IQ difference and CTG expansion difference in both the DM parent-child pairs and normal sib-affected sib pairs was poor, indicating that CTG expansion is not a reliable predictor of IQ either in individual persons or families. Further analysis of cognitive function in $D M$ is required to clarify specific deficits characteristic of this patient group.
\end{abstract}

(f Med Genet 1994;31:300-305)

Since the cloning of the myotonic dystrophy (DM) gene, ${ }^{1-3}$ and the discovery that an unstable CTG trinucleotide repeat sequence is present in those with the phenotype, it has been shown convincingly that the size of this triplet amplification is broadly correlated with disease severity according to age of onset of symptoms. ${ }^{4-7}$ It remains very difficult in an individual person, however, to predict the severity of the phenotype from the size of the CTG amplification except, possibly, at the extremities of the range of expansion observed. Amplification which is barely detectable by Southern blot analysis is associated with a mild or asymptomatic phenotype while large amplifications of $3 \mathrm{~kb}$ or greater are usually associated with a severe phenotype. Between these extremes of amplification disease severity is very variable. As yet, the question of whether or not individual clinical features of DM are well correlated with the molecular findings has not been addressed.

DM subjects are well known for their mental apathy, lack of motivation, and poor concentration. The earliest descriptions of DM were accompanied by observations of altered and disturbed mental affect..$^{8-10}$ These patients were variously described as having "peculiarities of temperament", 8 "intellectual enfeeblement", or "imbecility". ${ }^{10}$ Several detailed neuropsychological studies in DM, attempting to assess cognitive function qualitatively and quantitatively, have been undertaken in recent years. ${ }^{11-17}$ Mean intelligence quotient (IQ) scores in a total of $162 \mathrm{DM}$ subjects ranged from $84 \cdot 5^{16}$ to $96 \cdot 4,,^{13}$ with an overall mean of 91.6 (table 1). All studies used either the Weschler Adult Intelligence Scale (WAIS), or the WAIS-Revised (WAIS-R) to estimate IQ, and a variety of other scales were used either to verify cognitive deficit or to assess personality (table 1). Four of these studies were unaccompanied by controls ${ }^{12-15}$ and no study selected DM subjects across the full spectrum of the disease with all categories of clinical severity represented. No study has assessed intergenerational IQ deficit despite the well recognised "anticipation" in this disease. This is potentially important in genetic counselling for DM families, especially those for whom prenatal diagnosis is an option, where the diagnosis is dependent on the finding of an expanded CTG insertion.

The purposes of this study, therefore, were: (1) to establish an IQ profile of DM across the whole spectrum of disease severity; (2) to correlate IQ with both disease severity and CTG amplification; (3) to study anticipation of IQ and relate this to molecular findings; and (4) to study IQ differences between affected and unaffected sibs, and relate this to molecular findings.

\section{Methods}

SUBJECTS

DM patients

Recruitment for the study aimed at all known affected DM patients aged 16 to 75 years, across all degrees of clinical severity, in north east Scotland. Some available affected family members outside this region were also recruited. Retrospective and continuing ascertainment of DM cases has generated a prevalence figure of $1: 7610(13.1$ per 100000$)$ for Grampian region at 1 January 1990 (72 cases, 34 males, 38 females, 26 families; population $547940)$. The $55 \mathrm{DM}$ patients entered into the 
Table 1 Review of recent studies in which IQ and cognitive function have been assessed in myotonic dystrophy subjects

\begin{tabular}{|c|c|c|c|c|c|c|}
\hline \multirow[t]{2}{*}{ Reference } & \multicolumn{2}{|c|}{$D M$ cases } & \multicolumn{2}{|c|}{ Controls } & \multirow[t]{2}{*}{$I Q$ scale } & \multirow[t]{2}{*}{ Other scale(s) } \\
\hline & No & $I Q(S D)$ & No & $I Q(S D)$ & & \\
\hline $\begin{array}{l}11 \\
12 \\
13 \\
14 \\
15 \\
16 \\
17\end{array}$ & $\begin{array}{r}17 \\
29 \\
16 \\
18 \\
8 \\
37 \\
37\end{array}$ & $\begin{array}{l}95 \cdot 1(10 \cdot 8) \\
90 \cdot 3 \\
96 \cdot 4 \\
95 \cdot 4(19 \cdot 6) \\
85 \cdot 6(14 \cdot 2) \\
84 \cdot 5(13 \cdot 4) \\
94 \cdot 2(17 \cdot 8)\end{array}$ & $\begin{array}{l}25 \\
\overline{-} \\
\overline{2} \\
20\end{array}$ & $\begin{array}{l}112((9 \cdot 8) \\
\overline{-} \\
\overline{-} \\
106 \cdot 3(10 \cdot 7) \\
103 \cdot 4(7 \cdot 3)\end{array}$ & $\begin{array}{l}\text { WAIS } \\
\text { WAIS } \\
\text { WAIS-R } \\
\text { WAIS/WAIS-R } \\
\text { WAIS-R } \\
\text { WAIS-R } \\
\text { WAIS }\end{array}$ & $\begin{array}{l}\text { Halstead-Reitan SMT } \\
\text { Shipley-Hartford MMPI } \\
\text { Halstead-Reitan WMS } \\
\text { WMS, BVR } \\
\text { WMS, TMT, F-A-S, STROOP } \\
\text { MMSE } \\
\text { REY'S, RPM, BVR }\end{array}$ \\
\hline Total & 162 & \multicolumn{5}{|c|}{ e of mean values) } \\
\hline
\end{tabular}

WAIS-(R): Weschler Adult Intelligence Scale-(Revised); SMT: Story Memory Test; MMPI: Minnesota Multiphasic Personality Inventory; WMS: Weschler Memory Scale; BVR: Benton Visual Retention Test; TMT: Trail Making Test; MMSE: MiniMental State Examination; RPM: Raven's Progressive Matrices. In all tables, No= number of subjects or pairs.

study ( 27 males, 28 females, aged 16 to 74 years) therefore represent a homogeneous group relatively free of ascertainment bias. Diagnostic status was established clinically or by pedigree position or both in most subjects. In a small number diagnosis was determined by mutation analysis using pGB2. $6^{3}$ and PCR. Assignment of clinical severity status followed the system of Koch et al. ${ }^{18}$

(A) Mild, asymptomatic or minor muscular problems with onset $>40$ years, with or without lens changes or presenile cataracts.

(B) Adult, "classical" DM with myotonia and muscular weakness and wasting in the usual distribution, age of onset 21 to 40 years.

(C) Early adult, typical features of the disease but age of onset 11 to 20 years.

(D) Childhood, unusually early manifestation of signs and symptoms, aged 1 to 10 years, but without obvious signs during infancy.

(E) Congenital, severe manifestations of the disease in the neonatal period or infancy, with hypotonia, facial diplegia, respiratory distress owing to muscular weakness, feeding difficulties, and sometimes talipes.

\section{Controls}

There were thirty-one subjects, all at $50 \%$ pedigree risk of DM. The purpose of selecting this group was to minimise confounders owing to socioeconomic background and parental upbringing. They were well matched for age (table 2) but not for sex ratio (21 males, 10 females). Negative DM status was established clinically and by mutation analysis using pGB2.6 $6^{3}$ and PCR.

Table 2 Overall IQ profile of 55 myotonic dystrophy subjects and 31 controls at $50 \%$ risk

\begin{tabular}{|c|c|c|c|c|c|c|c|}
\hline \multirow[t]{2}{*}{ Subjects } & \multirow[t]{2}{*}{ No } & \multicolumn{3}{|l|}{$I Q$} & \multicolumn{3}{|l|}{ Age } \\
\hline & & Mean & $S D$ & Range & Mean & $S D$ & Range \\
\hline $\begin{array}{l}\text { DM cases } \\
\text { Total } \\
\text { Male } \\
\text { Female }\end{array}$ & $\begin{array}{l}55 \\
27 \\
28\end{array}$ & $\begin{array}{l}90 \cdot 2 \\
89.5 \\
90.8\end{array}$ & $\begin{array}{l}16 \cdot 1 \\
17 \cdot 0 \\
14 \cdot 6\end{array}$ & $\begin{array}{l}53-120 \\
56-120 \\
53-113\end{array}$ & $\begin{array}{l}40 \cdot 1 \\
36 \cdot 7 \\
43 \cdot 4\end{array}$ & $\begin{array}{l}15 \cdot 6 \\
13.8 \\
16 \cdot 7\end{array}$ & $\begin{array}{l}16-74 \\
16-67 \\
16-74\end{array}$ \\
\hline $\begin{array}{l}\text { Controls } \\
\text { Total } \\
\text { Male } \\
\text { Female }\end{array}$ & $\begin{array}{l}31 \\
21 \\
10\end{array}$ & $\begin{array}{r}102.6 \\
103.9 \\
99.7\end{array}$ & $\begin{array}{r}9 \cdot 4 \\
8 \cdot 6 \\
10 \cdot 7\end{array}$ & $\begin{array}{l}91-129 \\
92-129 \\
91-123\end{array}$ & $\begin{array}{l}38 \cdot 3 \\
37 \cdot 4 \\
40 \cdot 2\end{array}$ & $\begin{array}{l}14 \cdot 1 \\
13 \cdot 8 \\
16 \cdot 6\end{array}$ & $\begin{array}{l}18-69 \\
18-58 \\
23-69\end{array}$ \\
\hline
\end{tabular}

Unpaired $t$ test between the IQ of 55 DM subjects and the 31 controls: $\mathrm{p}=0.000$.

\section{IQ ASSESSMENT}

Assessments were undertaken by one interviewer (PT) using an abbreviated WAIS-R, suitable for adults aged 16 to 75 years. This consisted of vocabulary and arithmetic subsets.

The vocabulary subset used 35 words and subjects were asked to give the meaning of each in turn. Responses were scored 2,1 , or 0 , depending on accuracy, and five consecutive zero scores brought this part of the assessment to an end. The score achieved was converted into a "Scaled Score" according to age.

The arithmetic subset consisted of 14 questions to be answered without aids. Responses had to be completed within a specified time and four consecutive wrong answers brought this part of the assessment to an end. The score achieved was converted into a "Scaled Score" according to age. Combined Scaled Scores were converted into an IQ estimation by means of an equation devised by Crawford $e t$ $a^{19}$ (Department of Psychology, University of Aberdeen) in the following way.

(1) A full length WAIS-R was administered to a healthy adult population sample $(n=200)$ representative in terms of age, sex, and social class.

(2) Multiple regression analysis on this sample was used to build equations which produced full length IQ from the vocabulary and arithmetic subsets. As IQs are adjusted for age, age graded scaled scores for the two subsets were used as predictors.

\section{MUTATION ANALYSIS}

DNA was extracted from $20 \mathrm{ml}$ of blood by standard techniques. Patient DNA was digested with a fourfold excess of EcoRI and run overnight on $0.9 \%$ agarose gels at $30 \mathrm{~V}$. The digested DNA was blotted onto Hybond $\mathrm{N}+$ using $0.4 \mathrm{~mol} / 1 \mathrm{NaOH}$ in an LKB Vacugene blotter. Filters were prehybridised overnight at $65^{\circ} \mathrm{C}$ in a Techne hybridisation oven. The prehybridisation solution was as described by the manufacturer for Hybond $\mathrm{N}+$ and $10 \mu \mathrm{l}$ of sheared human DNA $(5 \mathrm{mg} / \mathrm{ml})$ was added to $20 \mathrm{ml}$ prehybridisation solution. The probe GB2. $6^{3}$ was labelled by random priming and hybridised to the filters for 16 to 24 hours. The filters were washed at $65^{\circ} \mathrm{C}$ in (1) $2 \times$ SSC, (2) $2 \times$ SSC, $0.1 \%$ SDS, and (3) 
$0.1 \times$ SSC for 10 minutes each wash. Autoradiography was for 24 to 48 hours at $-70^{\circ} \mathrm{C}$. PCR analysis used primers 101 and $102^{20}$ flanking the trinucleotide repeat. Approximately $20 \mathrm{ng}$ of genomic DNA was amplified in the presence of $\alpha 32 \mathrm{PdCTP}$ under similar conditions to those described by Brook et al. ${ }^{20}$ One tenth of PCR product was run on $8 \%$ denaturing polyacrylamide gels for two to three hours at $2000 \mathrm{~V}$. M13 DNA sequence was used as size standard. After electrophoresis the gels were dried and autoradiography carried out overnight at room temperature.

Assignment of DM patients to an " $E$ " category according to the size of their CTG expansion followed the system of Hunter et als:

E0, no detectable expansion on Southern blot analysis.

$\mathrm{E} 1,0$ to $1.5 \mathrm{~kb}$ expansion on Southern blot analysis.

E2, 1.5 to $3.0 \mathrm{~kb}$ expansion on Southern blot analysis.

E3, 3.0 to $4.5 \mathrm{~kb}$ expansion on Southern blot analysis.

$\mathrm{E} 4,>4.5 \mathrm{~kb}$ expansion on Southern blot analysis.

\section{STATISTICAL ANALYSIS}

The IQs of the total patient group were compared with those of controls by unpaired $t$ test.

The IQ distributions (fig 1 ) took the numbers of subjects in each division of 10 IQ points (50-59, 60-69, etc) and used the computer program "Cricket Graph" (Cricket Software) to construct the curves. IQ was correlated with disease severity according to age of onset and with CTG expansion size. IQs of the affected parent-child pairs and the normal sib-affected sib pairs were compared by paired $t$ test. In the

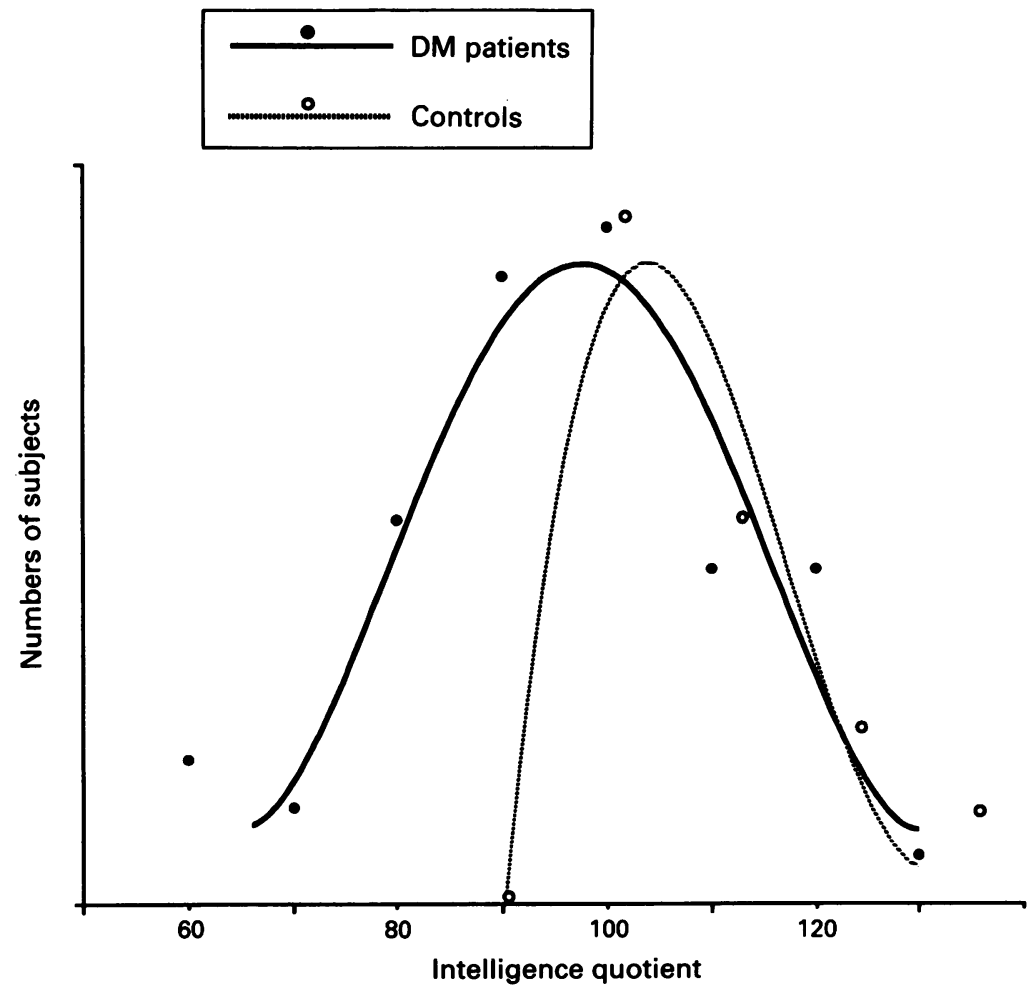

Figure 1 Distribution of intelligence quotient in 55 DM patients and 31 controls. case of the affected parent-child pairs the analysis comprised both the total group plus a separation of the pairs according to the sex of the affected parent. In families where an affected parent had more than one affected child, the average IQ of the affected children was calculated and used as one arm of the pair. Similarly, in large sibships, the average IQ of unaffected and affected sibs was calculated, as appropriate, to construct a "pair".

\section{Results}

ALL SUBJECTS

These results are presented in tables 2 to 4 and figs 1 to 3 . The mean IQ deficit between controls and affected subjects was $>12$ points, a highly significant difference. There was no significant sex difference in IQ for either the affected subjects or controls. The distribution of IQ in the affected group is compared with controls in fig 1 , where the modal values of the two distributions are closer than the means. When sorted according to clinical category by the criteria indicated in Methods (table 3), the mean IQs for the affected groups followed a near linear relationship with age of onset of symptoms (fig 2, coefficient of correlation 0.971). When sorted according to their CTG "E" (expansion) category (table 4), the correlation of IQ means with the degree of expansion was less linear (fig 3 , coefficient of correlation 0.923).

AFFECTED PARENT $V$ AFFECTED CHILD PAIRS The mean intergenerational IQ deficit in 15 parent-child pairs was $>11$ points, $p=0.02$ (table 5). The range, however, was very wide, from 37 to -23 points, and showed a very poor correlation when plotted against the CTG, expansion difference for each pair (fig 4). Analysis of the pairs according to sex of the affected parent showed that there was no significant intergenerational IQ difference where the affected parent was male $(n=16)$, but there was a significant IQ deficit of 17 points, $\mathrm{p}=0.025$, where the affected parent was female $(n=9$, table 6$)$.

Table $3 I Q$ of 55 DM subjects, clinical category according to age of onset of symptoms (see text for details)

\begin{tabular}{lrlll}
\hline Clinical category & No & Mean IQ & SD & Range \\
\hline A & 13 & $98 \cdot 9$ & $10 \cdot 4$ & $83-116$ \\
B & 28 & $93 \cdot 3$ & $11 \cdot 0$ & $76-116$ \\
D & 7 & $88 \cdot 1$ & $10 \cdot 5$ & $71-120$ \\
E & 3 & $71 \cdot 3$ & $6 \cdot 4$ & $64-76$ \\
& 4 & $57 \cdot 5$ & $5 \cdot 2$ & $53-65$ \\
\hline
\end{tabular}

Table 4 IO of 55 DM subjects by " $E$ " category $C T G$ expansion (for " $E$ " category details see text)

\begin{tabular}{lrrrl}
\hline $\begin{array}{l}\text { CTG expansion } \\
\text { category }\end{array}$ & No & Mean IQ & \multicolumn{1}{c}{$S D$} & Range \\
\hline E0 & 10 & $96 \cdot 1$ & $9 \cdot 9$ & $81-110$ \\
E1 & 19 & $102 \cdot 3$ & $10 \cdot 9$ & $83-120$ \\
E2 & 16 & $86 \cdot 2$ & $10 \cdot 1$ & $71-111$ \\
E3 & 9 & $68 \cdot 1$ & $11 \cdot 0$ & $53-83$ \\
E4 & 1 & $64 \cdot 0$ & - & - \\
\hline
\end{tabular}




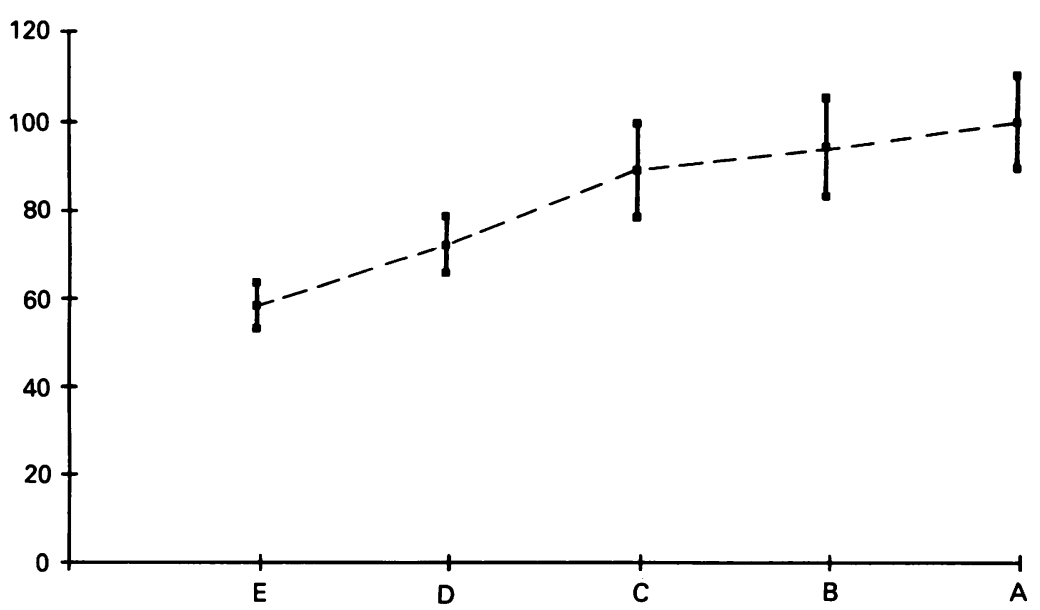

Figure $2 I Q$ profile of $55 \mathrm{DM}$ subjects sorted according to clinical severity (mean values, 1 SD) for each group. $X$ axis: clinical category by age of onset of symptoms (see text for details). Y axis: IQ assessment. Coefficient of correlation of the means: 0.971 .



Figure $3 I Q$ profile of $55 D M$ subjects sorted according to CTG expansion size (mean values, $1 S D$ ) for each group. $X$ axis: CTG expansion, " $E$ " category system (see text for details). $Y$ axis: $I Q$ assessment. Coefficient of correlation of the means: 0.923.

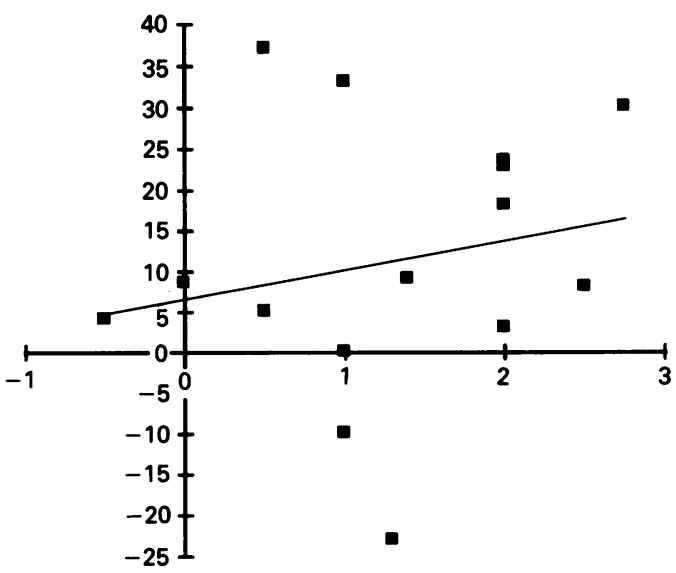

Figure 4 For 15 affected DM parent-child pairs: the $I Q$ difference ( $Y$ axis) plotted against the CTG expansion difference in kilobases ( $X$ axis).

function of the myotonin-protein kinase gene product is elucidated and related to neurophysiology and neuropathology. Present knowledge, to which this study contributes, is limited to descriptive analysis.

In this study one test of cognitive function, the abbreviated WAIS-R, was used by one observer in either the genetic clinic or the subjects' home in order to minimise variables associated with IQ measurement. The distribution of results in the control group (fig 1) suggests this was a reliable, reproducible

Table 6 IQ difference between 15 myotonic dystrophy parent-child pairs by sex of the affected parent

\begin{tabular}{lclll}
\hline Subjects & No & Mean IQ & $S D$ & Range \\
\hline Male DM parent & 6 & $98 \cdot 2$ & 14.5 & $78-116$ \\
DM child & 6 & 95.5 & 18.8 & $74-120$ \\
\hline
\end{tabular}

Paired $t$ test for intergenerational IQ deficit: $\mathrm{p}=0.4$

Female DM

\begin{tabular}{lrrrr} 
Female DM & & & & \\
parent & 9 & $100 \cdot 1$ & $11 \cdot 3$ & $83-113$ \\
DM child & 9 & $83 \cdot 1$ & $15 \cdot 1$ & $65-106$ \\
\hline
\end{tabular}

Paired $t$ test for intergenerational IQ deficit: $\mathrm{p}=0.025$

NORMAL SIB $V$ AFFECTED SIB PAIRS

The mean IQ deficit between normal and affected sibs in 15 pairs was $>10$ points, $\mathrm{p}=0.007$ (table 7). Again, the range was very wide, from 25 to -28 points. Correlation with the CTG expansion difference for each pair (fig 5) was closer than for the parent-child pairs (fig 4) but distorted by one value where the affected sib had a $1 \mathrm{~kb}$ expansion and significant muscular symptoms at the age of 24. Compared with his normal brother of 20 years, however, his IQ was 28 points higher.

\section{Discussion}

Progress in understanding the cognitive deficit in $\mathrm{DM}$ will begin to be possible only when the

Table 5 IQ difference between 15 myotonic dystrophy parent-child pairs

\begin{tabular}{lllll}
\hline Subjects & No & Mean IQ & $S D$ & Range \\
\hline DM parent & 15 & $99 \cdot 3$ & $12 \cdot 2$ & $78-116$ \\
DM child & 15 & $88 \cdot 1$ & $17 \cdot 2$ & $65-120$ \\
\hline
\end{tabular}

Paired $t$ test for intergenerational IQ deficit: $\mathrm{p}=0.02$.
Table 7 IQ difference between 15 normal sib-myotonic dystrophy sib pairs

\begin{tabular}{lllrl}
\hline Subjects & No & Mean IQ & \multicolumn{1}{c}{$S D$} & Range \\
\hline Normal sib & 15 & $100 \cdot 2$ & $7 \cdot 6$ & $92-116$ \\
DM sib & 15 & 89.6 & $13 \cdot 2$ & $71-120$ \\
\hline
\end{tabular}

Paired $t$ test for normal-affected intersib IQ deficit: $p=0.007$

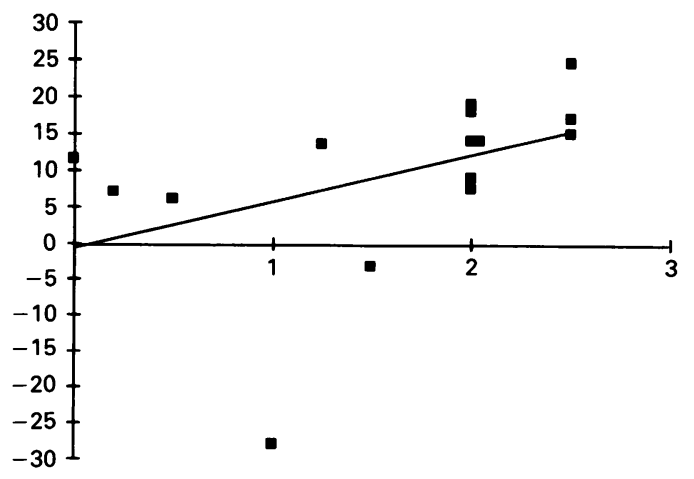

Figure 5 For 15 normal sib-affected DM sib pairs: the $I Q$ difference ( $Y$ axis) plotted against the CTG expansion difference in kilobases ( $X$ axis). 
method. In DM the assessment of clinical status by categories according to age of onset is imprecise since many patients are vague about when they were first aware of symptoms. Nevertheless it is possible to recognise broad categories of disease severity according to age of onset and the system of Koch et al ${ }^{18}$ was followed. Previous studies have shown a wide spread of IQ measurement in DM (table 1), ranging from $84 \cdot 5^{16}$ to $96 \cdot 4,,^{13}$ but the subjects of each study were selected and not representative of the full spectrum of disease severity. Nevertheless, the overall average IQ from these studies, 91.6 from a total of 162 subjects (table 1), is very close to our own mean of $90 \cdot 2$ from 55 subjects.

A large proportion of DM patients have an IQ in the normal range (fig 1) but many of these have cognitive difficulties which are concealed by the methodology of this study. In particular, many patients with a normal IQ admit to concentration problems and mental lethargy. For example, a newly diagnosed 16 year old female in our study, with an IQ of 104, admitted to concentration difficulties compared with her school peers, and academic reports consistently stated that she was performing below her potential. Studies which examined cognitive function in more detail have highlighted specific difficulties with attention and concentration, ${ }^{11} 14$ abstraction and new concept formation, ${ }^{112}$ and visuospatial tasks. ${ }^{12142122}$ In three studies a significant proportion had depression. ${ }^{141623}$ There was no evidence for deterioration of cognitive function with time, ${ }^{1221}$ as suggested by Maas and Paterson in $1937,{ }^{9}$ but a properly controlled longitudinal study has not been performed.

This study shows a reduction in IQ with the earlier onset of the disease (fig 2), contrasting the finding of Colombo et al. ${ }^{16}$ Others have failed to find a relationship between muscular symptoms and signs and the degree of cognitive impairment in DM. ${ }^{11223}$ This may have been partially because of sample size. It is possible, however, that widely varying patterns of somatic mosaicism for the CTG amplification account for such variation in phenotype. Indeed, in this study our examination of the CTG amplification in peripheral lymphocytes may not truly reflect genetic events in the tissue of interest, the central nervous system (CNS). Despite this possibility we have shown that there is a broad correlation of IQ with CTG expansion size (fig 3) across the full spectrum of disease severity. We have also shown a significant intergenerational IQ deficit (table 5) in 15 affected parent-child pairs. However, when analysed by the sex of the affected parent (table 6), only when the mutated gene was transmitted by females was the intergenerational IQ deficit significant. In this analysis the numbers were small, there being nine female and only six male, parents. Despite the small numbers these results provide further evidence that in general the disease in offspring is less severe when the father is the transmitting parent, consistent with the evidence that there is greater instability of the CTG repeat through female transmission. ${ }^{24}$
The observed intergenerational IQ deficit is most unlikely to be because of inadequate nurture since a significant difference was found between normal sibs at $50 \%$ risk and their affected sibs (table 7). These findings may prove useful in genetic counselling but caution is advised with respect to the usefulness of molecular studies in the prediction of intellectual performance in a person. Our results show a poor correlation between IQ and CTG expansion size differences for affected parents and their affected children (fig 4), a potentially important point when counselling for prenatal diagnosis. The correlation of IQ and CTG expansion size differences was much closer for the normal sib-affected sib pairs (fig 5) but it is clear from all analyses that intellectual performance cannot be reliably predicted from molecular findings, except, possibly, in the case of large CTG expansions of $3 \mathrm{~kb}$ or greater.

Further descriptive analysis includes magnetic resonance imaging (MRI) of the brain and EEG studies. MRI has shown increased subcortical white matter changes in a periventricular distribution bearing similarity to findings in demyelinating disorders. ${ }^{22} 25$ In addition, temporal lobe abnormalities, ${ }^{23}$ cerebral atrophy, ${ }^{23}$ and ventricular dilatation ${ }^{25} 26$ have been described. Patients with severe cognitive deficit tend to have the most striking abnormalities on cerebral imaging. Similarly, abnormalities of the EEG in DM, slow background and $\alpha$ wave activity, are most evident in subjects with severe cognitive impairment ${ }^{27-29}$ and, although not adequately explained, it is likely this represents cell membrane dysfunction in the CNS. The decrease in glucose uptake by the brain, described by Fiorelli et al, ${ }^{30}$ may also be a consequence of cell membrane abnormalities rather than a primary fall in cerebral metabolic rate or secondary to cortical atrophy. In DM, however, there is generalised glucose intolerance and insulin resistance, ${ }^{31}$ which makes the interpretation of this finding complex.

In the assessment of cognitive function in DM subjects a simple IQ measurement has limited value. For the general welfare of these patients further study should focus on specific deficits in performance with a view to designing the most appropriate aids and means of support that will enable this group to function optimally in society.

This work was supported by a grant from Grampian Health Board. Louise Blackmore gave invaluable advice on psychoBoar. Louine Bnd $\mathrm{Dr}$ John Crawford devised the abbreviated WAIS-R test. We are grateful for the willing cooperation of all WAIS-R test. We are gra

1 Harley HG, Brook JD, Rundle SA, et al. Expansion of an riation in myotonic dystrophy. Nature 1992;355:545-6.

2 Buxton J, Shelbourne P, Davies J, et al. Detection of an unstable fragment of DNA specific to individuals with myotonic dystrophy. Nature 1992;355:547-8.

3 Aslandis C, Jansen G, Amemiya C, et al. Cloning of the

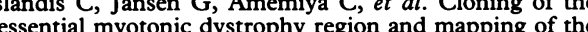
essential myotonic dystrophy region and

4 purle HG, Rundle SA, Reardon W, et al Unstable DNA sequence in myotonic dystrophy. Lancet 1992;339:11258.

5 Hunter A, Tsilfidis C, Mettler G, et al. The correlation of age of onset with CTG trinucleotide repeat amplification age of onset with CTG trinucleotide repeat amplificat

6 Tsilfidis C, Mackenzie AE, Mettler G, Barcelo J, Korneluk 
RG. Correlation between CTG trinucleotide repeat length and frequency of severe congenital myotonic dystrophy. Nature Genet 1992;1:192-5.

7 Harley HG, Rundle SA, MacMillan JC, et al. Size of the unstable CTG repeat sequence in relation to phenotype and parental transmission in myotonic dystrophy. $A m \mathcal{H}$ and parental transmission in

8 Adie WJ, Greenfield JG. Dystrophia myotonica (myotonia atrophica). Brain 1923;46:73-127.

9 Maas O, Paterson AS. Mental changes in families affected by dystrophia myotonica. Lancet $1937 ; \mathbf{i}: 21-3$.

10 Mackie JRM. Dystrophia myotonica. MD thesis, University of Aberdeen, 1934

11 Woodward JB, Heaton RK, Simon DB, Ringel SP. Neuropsychological findings in myotonic dystrophy. f Clin Neuropsychol 1982;4:335-42.

12 Bird TD, Follett C, Griep E. Cognitive and personality function in myotonic muscular dystrophy. $₹$ Neurol Neurosurg Psychiatry 1983;46:971-80.

13 Portwood MM, Wicks JJ, Lieberman JS, Fowler WM Psychometric evaluation in myotonic muscular dystrophy. Arch Phys Med Rehabil 1984;65:533-6.

14 Brumback RA. Disturbed personality and psychosocial adjustment in myotonic dystrophy: relationship to intellectual/cognitive function and underlying affective disorder (depression). Psychol Rep 1987;60:783-96.

15 Broughton R, Stuss D, Kates M, Roberts J, Dunham W. Neuropsychological deficits and sleep in myotonic dysNeuropsychological deficits and sleep in

16 Colombo G, Perini GI, Miotti MV, Armani M, Angelini C. Cognitive and psychiatric evaluation of 40 patients with myotonic dystrophy. Ital F Neurol Sci 1992;13:53-8.

17 Sinforiani E, Sandrini G, Martelli A, et al. Cognitive and neuroradiological findings in myotonic dystrophy. Funct Neurol 1991;6:377-84

18 Koch MC, Grimm T, Harley HG, Harper PS. Genetic risks for children of women with myotonic dystrophy. $A m$ Hum Genet 1991;48:1084-91.

19 Crawford JR, Allan KM, Jack AM. Short-forms of the UK WAIS-R: regression equations and their predictive validity in a general population sample. $\mathrm{Br} \mathrm{F}$ Clin Psychol 1992;31:191-202.
20 Brook JD, McCurrach ME, Harley HG, et al. Molecular basis of myotonic dystrophy: expansion of a trinucleotide (CTG) repeat at the $3^{\prime}$ end of a transcript encoding a protein kinase family member. Cell 1992;68:799-808.

21 Censori B, Danni M, Del Pesce M, Provinciali L. Neuropsychological profile in myotonic dystrophy. $f$ Neurol psychological p

22 Ragazzoni A, Pinto F, Taiuti R, Silveri MC. Myotonic dystrophy: an electrophysiological study of cognitive defidystrophy: an electrophysiological study

23 Huber SJ, Kissel JT, Shuttleworth EC, Chakeres DW, Clapp LE, Brogan MA. Magnetic resonance imaging and clinical correlates of intellectual impairment in myotonic dystrophy. Arch Neurol 1989;46:536-40.

24 Lavedan C, Hofmann-Radvanyi $\mathrm{H}$, Shelbourne $\mathrm{P}$, et al. Myotonic dystrophy: size- and sex-dependent dynamics of CTG meiotic instability, and somatic mosaicism. $A m^{f}$ Hum Genet 1993;52:875-83.

25 Glantz RH, Wright RB, Huckman MS, Garron DC, Siegel IM. Central nervous system magnetic resonance imaging indings in myotonic dystrophy. Arch Neurol 1988;45:36-

26 Garcia-Alix A, Cabanas F, Morales C, Paisan L, Quero J. Brain abnormalities in congenital myotonic dystrophy. David W Smith Workshop on Malformations and Morphogenesis, Madrid, Spain, 23-29 May 1989. Proc Greenphogenesis, Madrid, Spain, 23-2

27 Friedlander WJ, Bittenbender JB. EEG findings in myotonia dystrophica. Electroencephalogr Clin Neurophysiol 1964;17:564-6.

28 Lundervold A, Refsum S, Jacobsen W. The EEG in dystrophia myotonica. Eur Neurol 1969;2:279-84.

29 Beijersbergen RSHM, Kemp A, Storm Van Leeuwen W. EEG observations in dystrophia myotonica (Curschmann-Steinert). Electroencephalogr Clin Neurophysiol 1980;49:143-51.

30 Fiorelli M, Duboc D, Mazoyer BM, et al. Decreased cerebral glucose utilisation in myotonic dystrophy. Neurology 1992;42:91-4.

31 Moxley RT, Corbett AJ, Minaker KL, Rowe JW. Whole body insulin resistance in myotonic dystrophy. Ann Neurol 1984;15:157-62. 